\begin{tabular}{c|c|c}
\hline & MARINE ECOLOGY PROGRESS SERIES \\
Vol. 273: 251-267, 2004 & Mar Ecol Prog Ser & Published June 8 \\
\hline \hline
\end{tabular}

\title{
Strength, slope and variability of marine latitudinal gradients
}

\author{
Helmut Hillebrand ${ }^{1,2, *}$ \\ ${ }^{1}$ Institute for Marine Research, University of Kiel, Section for Marine Ecology, Düsternbrooker Weg 20, 24105 Kiel, Germany \\ ${ }^{2}$ Present address: Institute for Botany, University of Cologne, Gyrhofstrasse 15, 50931 Cologne, Germany
}

\begin{abstract}
Latitudinal declines of species richness from the tropics to the poles represent a general spatial pattern of diversity on land. For the marine realm, the generality of this pattern has frequently been questioned. Here, I use a database with nearly 600 published gradients (198 of which were marine) to assess whether there is a marine latitudinal diversity gradient of similar average strength and slope as that for terrestrial organisms. Using meta-analysis techniques, I also tested which characteristics of organisms or habitats affected gradient strength and slope. The overall strength and slope of the gradient for marine organisms was significantly negative and of similar magnitude compared to gradients for terrestrial organisms. Marine gradients were on average stronger as well as steeper than freshwater gradients. Latitudinal gradients were clearly a regional phenomenon, with stronger gradients and steeper slopes for diversity assessed on regional than on local scales. The gradient parameters differed also between oceans and between different habitats, with steeper gradients related to the pelagial rather than the benthos. There were on the other hand no significant differences between hemispheres and between different gradient ranges, although such differences have often been presumed. The most important organismal characteristic related to gradient structure was body mass, with significant gradients related to large organisms. A significant increase in gradient strength with increasing trophic level was observed. The meta-analysis also revealed strongest gradients for nekton and mobile epifauna, whereas the gradients were weak for sessile epifauna and for infauna. In conclusion, marine biota reveal a similar overall decline in diversity with latitude to that observed in terrestrial realms, but the strength and slope of the gradient are clearly subject to regional, habitat and organismal features.
\end{abstract}

KEY WORDS: Diversity $\cdot$ Latitude $\cdot$ Evolution $\cdot$ Dispersal $\cdot$ Meta-analyses $\cdot$ Macroecology $\cdot$ Habitat type

Resale or republication not permitted without written consent of the publisher

\section{INTRODUCTION}

The latitudinal decline of species richness is the most general and most robust spatial pattern of biological diversity. The increase in species richness towards the tropics was early recognised by naturalists (Humboldt 1828, Hawkins 2001) and has been described for a large number of organisms (Fischer 1960, Pianka 1966, Huston 1994, Hillebrand \& Azovsky 2001). A few notable exceptions have been reported, such as aquatic macrophytes (Bolton 1994), ichneumonid insects (Owen \& Owen 1974), sediment infauna (Thorson 1952) and unicellular eukaryotes (Hillebrand \&
Azovsky 2001). Despite the long and intensive research effort, there is still an astonishing lack of consensus about the mechanisms leading to this gradient (Pianka 1966, Rohde 1992).

Much of the discussion on latitudinal gradients is confined to terrestrial biota, whereas several of the exceptional taxa-showing no or reversed gradients dwell in marine habitats. A decade ago, Clarke (1992) asked whether there is a general latitudinal decline of diversity in the sea. Although some groups showed strong longitudinal gradients, Clarke (1992) showed several examples where gradients were lacking. Discussing high polar diversity in the southern hemi- 
sphere (see also Brey et al. 1994) and several methodological issues, Clarke (1992) concluded that there was no convincing evidence for a general latitudinal diversity trend for marine biota. Moreover, he stated that there was no consensus on which scale the diversity gradient should be assessed. In the decade following that publication, a large number of marine organisms were investigated and significant latitudinal gradients were found (Rex et al. 1993, 2000, Roy et al. 1998, 2000b, Gray 2002 [for the northern hemisphere], Macpherson 2002) or not found (Wilson 1998, Barnes \& Arnold 2001, Ellingsen \& Gray 2002, Gray 2002 [for the southern hemisphere]). It is thus still open to question whether marine latitudinal gradients are as consistent as terrestrial ones and which factors would explain the differences between marine and terrestrial realms. In addition to comparing the average gradient strength and slope between marine and other realms, it is important to identify factors affecting gradient strength and slope in the marine realm. These factors may be regional differences in ecosystems (between oceans or hemispheres), differences between habitats (coastal vs deep-sea benthos) or between organisms (from large mobile consumers to small planktonic producers). The generality (average strength and slope) and the variation in latitudinal gradients are the 2 main subjects of this paper.

The lack of an overall picture on how important the latitudinal pattern is in the sea is connected to the fact that latitudinal gradients are often investigated for single groups of organisms and underlying causes are often corroborated by simple covariation between diversity, latitude and a 3rd variable proposed to explain the gradient (Currie et al. 1999). Meta-analysis can be used to analyse the latitudinal diversity gradient generally (Gurevitch \& Hedges 1993, Rosenberg et al. 2000, Hillebrand \& Azovsky 2001), and allows one to test how the latitudinal gradient differs for different subsets of the earth's biota and regions. In addition to testing average gradient strength and slope for different realms (marine vs terrestrial), the analysis allows identification of variables (organismal traits, habitat types, regions) that significantly affect gradient structure. As for any reviewing and summarising technique, the increase in generality is connected to a decrease in resolution. Without doubt, marine diversity patterns are more complex than simple trends with latitude: (1) regional hotspots and coldspots of diversity exist for different groups of marine organisms (Hughes et al. 2002, Price 2002, Worm et al. 2003); (2) there are strong regional aspects of diversity (Gray 2001a, Ellingsen \& Gray 2002); (3) diversity does not necessarily peak at the equator (Rutherford et al. 1999); and (4) diversity is obviously not similar north and south of the equator
(Gray 2001b, 2002). However, the overarching question remains: does the marine realm harbour more of such regional diversity patterns modifying the latitudinal gradient than the terrestrial realm?

For an overall assessment of the generality of the latitudinal gradient, I assembled data from nearly 600 gradients of diversity with latitude described in the literature. In a previous contribution (Hillebrand 2004) I analysed large-scale trends for all kinds of biota and habitats across marine, terrestrial and freshwater systems. Here, I focus on questions pertaining to the marine realm, which was represented by 198 gradients. I tested the following hypotheses on marine habitats and organisms: (1) there is a significant overall decline of marine diversity with latitude, i.e. average gradient strength and slope are significantly negative; (2) the average strength and slope of the marine gradients are of similar magnitude to those for terrestrial and freshwater organisms; (3) the gradient strength and slope differ between different marine regions, organisms and habitat types.

\section{MATERIALS AND METHODS}

Data. Information on latitudinal gradients was obtained from the literature; for a detailed account see Hillebrand (2004). I used 4 abstracting services and databases to assemble the information: Cambridge Biological Abstracts, ISI Web of Science, JSTOR, and the Aquatic Science and Fisheries Abstracts. Identical search strings ('latitudinal gradient', 'latitude AND diversity' or 'latitude AND species richness') were used in these databases. Additionally, recent reviews were searched (Rohde 1992, 1999, Huston 1994, Rosenzweig 1995, Currie et al. 1999) as well as the bibliography of the papers detected. From a total of more than 1000 studies checked, 232 studies conformed to the following selection criteria: (1) the number of observations had to be 3 or more; (2) the range of latitudes covered had to be at least 10 degrees; (3) if only 3 or less sites were investigated, they had to be placed in the same continent or ocean (thus avoiding comparisons between, for example, tropical diversity in Asia and temperate diversity in North America). The general approach was rather inclusive than exclusive, since arbitrary deletion of studies may strongly bias the outcome of the analysis (Englund et al. 1999). Therefore, the studies included here will obviously differ in quality and in resolution. A major advantage of metaanalysis is, however, that studies are weighted by a measure of uncertainty. For example, a study on 3 sites in the less well known Pacific has considerably less impact on the overall results than a study on 300 well investigated sites in the Atlantic. 
Meta-analyses (and other reviewing techniques) can suffer from a publication bias, resulting in data material which mainly contains significant results (Gurevitch \& Hedges 1999, Blenckner \& Hillebrand 2002, Kotiaho \& Tomkins 2002). Moreover, meta-analyses may be influenced by unrepresentative selection of organisms in the primary studies (Hillebrand \& Blenckner 2002) and the use of arbitrary selection criteria in assembling the database (Englund et al. 1999). The latter was avoided by using very unrestrictive selection criteria (see above). To broaden the basis of this analysis and to avoid the impact of publication bias, I also included studies that were not originally designed to test for latitudinal gradients, but which reported diversity measures for local habitats or regions across different latitudes.

The 232 studies included in this analysis reported 581 gradients of diversity with latitude. Each of these gradients represents the assessment of diversity of a particular group of organisms, which were either taxonomically or functionally defined, at different latitudes. A complete electronic appendix containing all details on the gradients and studies is published together with a more general analysis of these data (Hillebrand 2004).

For each gradient, I obtained the correlation coefficient $(r)$ between latitude and diversity, as well as the slope $(b)$, its standard error $\left(\mathrm{SE}_{b}\right)$ and the intercept $(a)$ of the linear regression of diversity on latitude. These values were used to calculate the strength and the slope of each gradient. The gradient strength was defined as Fisher's z-transform of $r\left(r_{Z}\right)$, which was calculated as:

$$
r_{z}=\frac{1}{2} \times \ln \left(\frac{1+r}{1-r}\right)
$$

For each value of $r_{Z}$, sampling variance was calculated from the number of observations (N) included in the gradient as:

$$
\operatorname{var}_{r_{z}}=\frac{1}{N-3}
$$

The slope (b) was also used in a weighted metaanalysis with the square of the standard error as the variance estimate (Hillebrand et al. 2001). The slope and the correlation coefficients are not entirely independent parameters of a linear relationship, but separate analysis is warranted by the different aspects measured by the 2 effect sizes (Hillebrand 2004).

Classifications. The gradients were classified with respect to variables characterising the organismal group, the habitat type, the geography, the scale and analytical details of each study (see Hillebrand 2004 for additional details). These classifications were chosen to allow objective assignment of levels to the different studies. Therefore, bold categories were favoured over more detailed, but also more speculative, units. Organismal groups were characterised in a 'functional' and a taxonomic category. The 'functional' differentiation comprised microalgae, macrophytes, protozoa, crustacean zooplankton, other zooplankton, meiofauna, arthropod zoobenthos, colonial zoobenthos, molluscan zoobenthos, other zoobenthos, fish, other vertebrates, parasites. These functional groups are obviously not homogeneous, but describe organisms sharing some of their characteristics (body size, trophic role, habitat use). These groups are used to test for broad differences in the strength or slope of the gradients, but not to infer any common evolutionary history. The taxonomic differentiation was at phylum level (Bacillariophyta, Spermatophyta, Arthropoda, Chordata, Cnidaria, Porifera, Tentaculata, Mollusca, Nemathelminthes, Annelida, Echinodermata, Plathelminthes, Protozoa, Chaetognatha). For each type of organism, the mode of dispersal (flying, own mobility, pelagic larvae, pelagic adults, seeds/spores, and parasitic transfer) and the most prominent life form (nekton, mobile epifauna, sessile epifauna, infauna, plankton, flying, parasite) were noted. When organisms had different dispersal or life forms, the assignment of a level followed the majority of species. Moreover, the trophic position was characterised in broad categories (such as carnivores, herbivores, autotrophs or omnivores). All groups containing different trophic levels, such as annelids, were assigned omnivores, which therefore represents a very broad category. Mean organism body mass was noted (log g wet weight) from estimates published in the literature (Hillebrand 2004). Many estimates were available as ranges for a certain organismal group (Peters 1983). To acknowledge the higher number of smaller organisms in any size range, I used the mean of the log-transformed range.

Besides categorising the realm (marine, freshwater, terrestrial), the type of habitat was characterised in broad categories as either pelagic (subdivided into coastal or open ocean), benthic (subdivided into coastal or deep sea), estuaries or host biota (for parasites). The geographic position of the gradient was characterised by (1) hemisphere (either northern, southern or both, the latter for analyses not differentiating between northern or southern position) and (2) the longitude (Atlantic, Pacific, Indian Ocean, world-wide).

Spatially, I characterised the study as either regional or local due to its sampling grain: all studies reporting diversity for certain sites or sampling points were defined as local, which corresponds to the measurement of $\alpha$-diversity within samples or habitats (Whittaker 1960); all studies using regional scales by using provinces or latitudinal grids were designated as regional ( $\gamma$-diversity) (Hillebrand 2004). To analyse whether the inclusion of 
polar seas would affect the latitudinal gradients due to the proposed high polar diversity (Clarke 1992, Brey et al. 1994), I characterised the spatial extent of the gradient in 3 variables: minimum latitude, maximum latitude and latitude range (max-min). The minimum latitude is that nearest the equator in the original study, and the maximum is the most poleward.

Statistics. Weighted meta-analysis on $r_{Z}$ and $b$ was used to calculate average magnitudes for gradient strength or slope and to detect significant differences between data obtained from different studies (Gurevitch \& Hedges 1993, 1999, Rosenberg et al. 2000, Hillebrand et al. 2001). Grand mean effect sizes $\left(E^{++}\right)$ and their $95 \%$ confidence intervals (CI) were obtained using the bootstrapping procedure in MetaWin 2.0 (Rosenberg et al. 2000). Difference of the CI from zero indicated significant average gradient strengths and slopes.

For all classification variables, meta-analyses were used to calculate group-wise effect sizes $\left(\mathrm{E}^{+}\right)$and their CIs. An analysis of heterogeneity divided the total heterogeneity in the effect sizes into heterogeneity explained by the categorical variables $\left(Q_{\mathrm{b}}\right)$ and residual heterogeneity $\left(Q_{\mathrm{w}}\right)$. A mixed effect model was used throughout (Gurevitch \& Hedges 1993, 1999, Rosenberg et al. 2000, Hillebrand et al. 2001), which avoids the assumption that there is 1 true effect size for the entire data set or a category within a grouping variable. Significance levels for the analysis of heterogeneity were obtained from 25000 randomisations. Significantly different variable categories were assigned from non-overlapping CIs. For the continuous variables, a weighted regression was used (Rosenberg et al. 2000), where slope and intercept were calculated and the significance was tested by the heterogeneity explained by the regression model.

Multiple use of data requires adjustment of significance levels, which was done using a Bonferroni adjustment of $\mathrm{p}$ (Sokal \& Rohlf 1995), with $\mathrm{p}_{\mathrm{adj}}=\mathrm{p} \times k$ and $k=$ the number of variables used $=14$. Bonferroni adjustments are known to be highly conservative; therefore, I not only discuss significant differences $\left(\mathrm{p}_{\mathrm{adj}}<0.05\right)$, but also trends with $\mathrm{p}_{\mathrm{adj}}<0.15$ (corresponding to $\mathrm{p}<0.01$ prior to adjustment).

For $r_{Z}$, the actual measure of diversity did not significantly affect the effect size (meta-analysis, $p_{\text {adj }}=0.269$ ). For $b$, however, the difference between the measures was significant $\left(p_{\text {adj }}=0.001\right)$, with species richness resulting in steeper slopes than any other measure. Therefore, I restricted all forthcoming analyses involving $b$ to those employing species richness as the diversity measure.

\section{RESULTS}

\section{The overall strength of marine latitudinal gradients}

$\mathrm{E}^{++}$for both response variables $\left(r_{Z}, b\right)$ were negative and differed significantly from zero (Table 1). Over the wide range of organisms and habitats covered, marine organisms showed a significant latitudinal decline of diversity towards the poles. Moreover, marine gradients had average magnitudes of strength and slope similar to those of terrestrial ones, and both marine and terrestrial gradients were significantly stronger and steeper than freshwater gradients (Table 1). For gradient strength, the highest $\mathrm{E}^{++}$ was found in the marine realm, although the difference to the terrestrial realm was not significant (overlapping CI). The average decline of marine diversity with latitude was significant even though 66 of the 198 original reported gradients were not significant. Thus, there is a clear gradient generalised over all marine taxa, even when many non-significant data are included.

A clear separation between regional and local scales was found for both slopes and strengths (Fig. 1). Latitudinal gradients were on average both

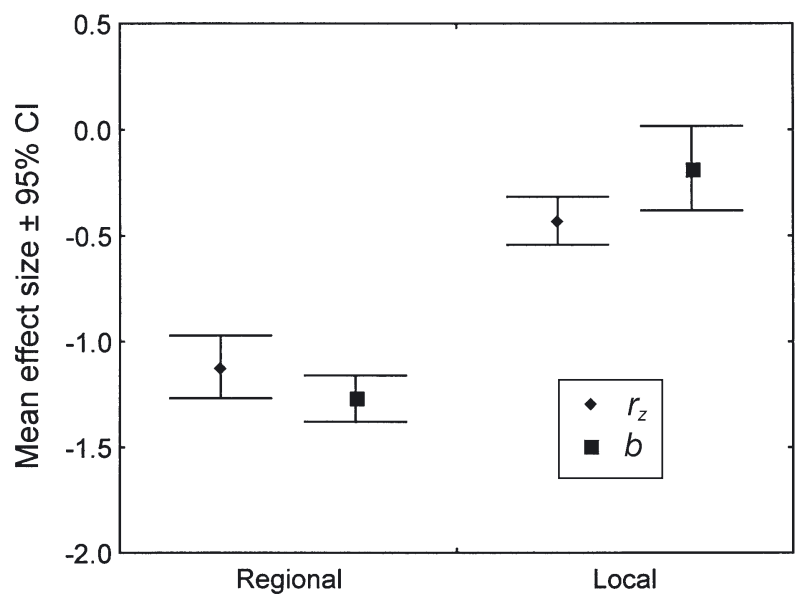

Fig. 1. Mean effect sizes $( \pm 95 \%$ confidence intervals, CI) for slope $(b)$ and strength $\left(r_{Z}\right)$ of the latitudinal gradient of diversity separated for local and regional data sets

Table 1. Grand mean effect sizes $\left(\mathrm{E}^{++}\right)$and their $95 \%$ confidence intervals (CI) for gradient strength $\left(r_{Z}\right)$ and slope $(b)$ for marine, freshwater and terrestrial gradients of diversity with latitude ( $k=$ number of gradients)

\begin{tabular}{|c|c|c|c|c|c|c|}
\hline \multirow{2}{*}{ Realm } & \multirow[t]{2}{*}{$k$} & & $r$ & \multirow{2}{*}{$k$} & $\longrightarrow$ & \multirow[b]{2}{*}{$\mathrm{CI}$} \\
\hline & & $E^{++}$ & $\mathrm{CI}$ & & $\mathrm{E}^{++}$ & \\
\hline Marine & 198 & -0.82 & -0.93 to -0.71 & 129 & -1.10 & -1.40 to -0.84 \\
\hline Freshwater & 68 & -0.26 & -0.40 to -0.12 & 42 & -0.21 & -0.38 to -0.06 \\
\hline Terrestrial & 286 & -0.79 & -0.87 to -0.71 & 199 & -1.25 & -1.49 to -1.04 \\
\hline
\end{tabular}


stronger and steeper for regional data sets $(\gamma$-diversity) than for local ones ( $\alpha$-diversity). This difference was significant for both $r_{Z}$ and $b$ (Table 2). However, even the local effect size remained significantly different from zero. To avoid biasing results in the analyses, I separated all forthcoming analyses into regional and local data sets.

\section{Geographical position of the study}

Regional gradient strength was significantly different between oceans (Table 3); the difference pertained

Table 2. Analysis of heterogeneity for gradient scale (regional or local) on gradient strength $\left(r_{Z}\right)$ and slope $(b)$ for marine latitudinal patterns. The table gives the response variable, the degrees of freedom (df) and the heterogeneity $(Q)$ between (bet.) and within (with.) categories and the adjusted significance level $\left(\mathrm{p}_{\text {adj }}\right)$

\begin{tabular}{|lcrrrr|}
\hline Variable & $\mathrm{df}_{\text {bet. }}$ & $Q_{\text {bet. }}$ & $\mathrm{df}_{\text {with. }}$ & $Q_{\text {with. }}$ & $\mathrm{p}_{\text {adj }}$ \\
\hline$r_{Z}$ & 1 & 62.32 & 188 & 243.56 & $<0.001$ \\
$b$ & 1 & 94.19 & 127 & 1448.32 & $<0.001$ \\
\hline
\end{tabular}

to significantly stronger gradients in the Atlantic than in any other ocean (Fig. 2a). Local gradient strength also differed significantly between oceans, but without such clear differences. A non-significant contrast was observed in regional slopes (Table 3), where steep but variable declines of diversity were observed in the Indian Ocean, whereas the Atlantic and Pacific Oceans had similar and flatter average slopes (Fig. 2d). On a regional scale, the average slope and strength was significantly negative for all oceans, except for the Pacific Ocean (Fig. 2a,d).

The strength and slope of the gradient did not differ between the northern and southern hemispheres (Table 3 ), and $\mathrm{E}^{+}$were almost identical for both parameters (Fig. 2b,e). Studies comprising data from both hemispheres showed slightly weaker gradients on regional scales (Fig. 2b) compared to those restricted to either northern or southern hemispheres. Again, all $\mathrm{E}^{+}$on regional scales were significantly negative (Fig. 2b,e)

The spatial extension of the gradient was analysed by 3 continuous variables: the minimum latitude, the maximum latitude and the range of latitudes observed. The minimum latitude did not affect slope or strength on any scale (Table 3 ). The maximum latitude affected only local slopes, where gradients

Table 3. Analysis of heterogeneity on gradient strength $\left(r_{Z}\right)$ and slope $(b)$ for regional and local marine latitudinal diversity patterns. The table gives the category and response variable, the degrees of freedom (df), the heterogeneity (Q) between (bet.) and within (with.) categories and the adjusted significance level $\left(\mathrm{p}_{\text {adj }}\right)$

\begin{tabular}{|c|c|c|c|c|c|c|c|c|c|c|c|}
\hline \multirow{2}{*}{ Category } & \multirow{2}{*}{ Variable } & \multicolumn{5}{|c|}{-Regional } & \multirow{2}{*}{$\overline{\mathrm{df}_{\text {bet. }}}$} & \multirow[b]{2}{*}{$Q_{\text {bet. }}$} & \multirow{2}{*}{$\begin{array}{l}\text { - Local } \\
\mathrm{df}_{\text {with. }}\end{array}$} & \multirow[b]{2}{*}{$Q_{\text {with }}$} & \multirow[b]{2}{*}{$\mathrm{p}_{\text {adj }}$} \\
\hline & & $\mathrm{df}_{\text {bet. }}$ & $Q_{\text {bet. }}$ & $\mathrm{df}_{\text {with. }}$ & $Q_{\text {with. }}$ & $\mathrm{p}_{\mathrm{adj}}$ & & & & & \\
\hline \multirow[t]{2}{*}{ Longitude } & $r_{Z}$ & 3 & 73.21 & 104 & 116.91 & $<0.001$ & 3 & 15.88 & 78 & 94.07 & 0.043 \\
\hline & $b$ & 3 & 25.33 & 93 & 1171.82 & 1 & 3 & 7.10 & 28 & 62.32 & 1 \\
\hline \multirow[t]{2}{*}{ Hemisphere } & $r_{Z}$ & 2 & 11.25 & 104 & 121.07 & 0.115 & 2 & 3.73 & 79 & 71.32 & 1 \\
\hline & $b$ & 2 & 15.50 & 93 & 1170.10 & 1 & 2 & 5.08 & 29 & 56.70 & 1 \\
\hline \multirow[t]{2}{*}{ Range } & $r_{Z}$ & 1 & 8.34 & 102 & 123.39 & 0.054 & 1 & 37.03 & 80 & 84.12 & $<0.001$ \\
\hline & $b$ & 1 & 0.01 & 95 & 1205.09 & 1 & 1 & 19.29 & 30 & 67.29 & $<0.001$ \\
\hline \multirow[t]{2}{*}{ Minimum } & $r_{Z}$ & 1 & 2.63 & 102 & 118.48 & 1 & 1 & 6.31 & 78 & 79.74 & 0.168 \\
\hline & $b$ & 1 & 0.41 & 95 & 1207.89 & 1 & 1 & 5.91 & 30 & 61.80 & 0.210 \\
\hline \multirow[t]{2}{*}{ Maximum } & $r_{Z}$ & 1 & 6.70 & 102 & 124.18 & 0.126 & 1 & 18.65 & 78 & 65.92 & 0.833 \\
\hline & $b$ & 1 & 0.15 & 95 & 1205.77 & 1 & 1 & 11.71 & 30 & 70.41 & 0.009 \\
\hline \multirow[t]{2}{*}{ Habitats } & $r_{Z}$ & 4 & 18.76 & 103 & 112.49 & 0.065 & 5 & 19.05 & 76 & 93.41 & 0.047 \\
\hline & $b$ & 4 & 86.90 & 92 & 1046.96 & 0.644 & 4 & 10.60 & 27 & 69.69 & 1 \\
\hline \multirow[t]{2}{*}{ Body weight } & $r_{Z}$ & 1 & 8.84 & 99 & 118.18 & 0.041 & 1 & 2.83 & 80 & 80.71 & 1 \\
\hline & $b$ & 1 & 55.46 & 95 & 1144.78 & $<0.001$ & 1 & 0.51 & 30 & 63.85 & 1 \\
\hline \multirow[t]{2}{*}{ Trophic position } & $r_{Z}$ & 6 & 21.24 & 101 & 121.80 & 0.117 & 6 & 11.73 & 75 & 84.48 & 1 \\
\hline & $b$ & 6 & 106.43 & 90 & 1036.17 & 1 & 5 & 13.51 & 25 & 48.83 & 1 \\
\hline \multirow[t]{2}{*}{ Life form } & $r_{Z}$ & 6 & 41.19 & 100 & 111.94 & 0.002 & 5 & 19.78 & 66 & 85.76 & 0.061 \\
\hline & $b$ & 5 & 80.73 & 90 & 1090.61 & 1 & 4 & 14.83 & 21 & 47.85 & 1 \\
\hline \multirow[t]{2}{*}{ Dispersal mode } & $r_{Z}$ & 5 & 16.25 & 102 & 113.69 & 0.295 & 4 & 6.73 & 77 & 88.96 & 1 \\
\hline & $b$ & 5 & 69.30 & 91 & 1095.40 & 1 & 2 & 4.71 & 29 & 71.49 & 1 \\
\hline \multirow[t]{2}{*}{ Organismal group } & $r_{Z}$ & 11 & 94.91 & 94 & 94.91 & $<0.001$ & 10 & 43.44 & 71 & 99.42 & 0.006 \\
\hline & $b$ & 9 & 102.69 & 85 & 1027.47 & 1 & 6 & 20.10 & 22 & 44.90 & 1 \\
\hline \multirow[t]{2}{*}{ Phylum } & $r_{Z}$ & 9 & 32.30 & 89 & 11.23 & 0.091 & 9 & 27.16 & 59 & 79.19 & 0.083 \\
\hline & $b$ & 5 & 46.82 & 80 & 1051.43 & 1 & 6 & 16.74 & 15 & 29.85 & 1 \\
\hline
\end{tabular}



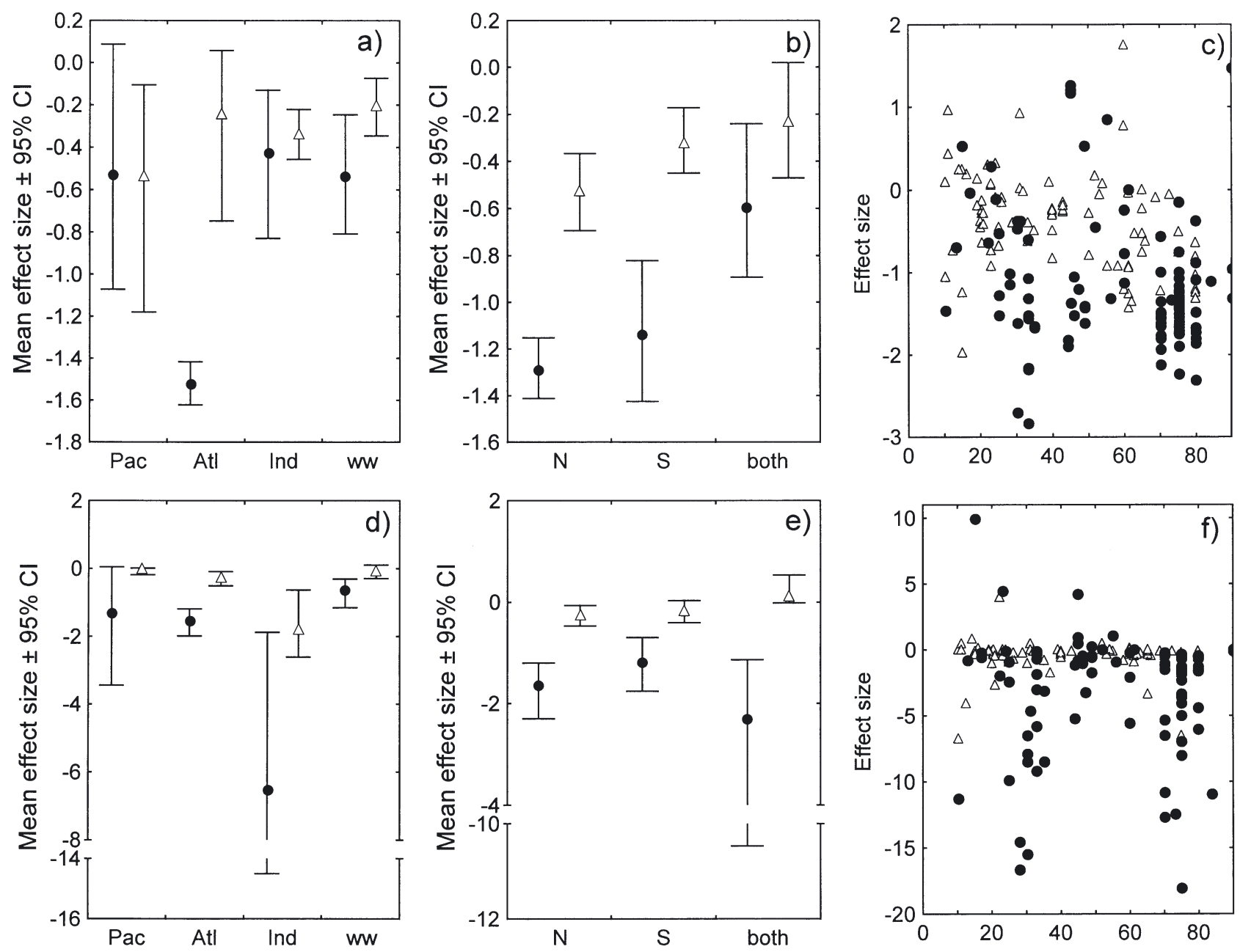

Fig. 2. Mean effect sizes $\left( \pm 95 \%\right.$ confidence intervals, CI) for $(\mathrm{a}-\mathrm{c})$ strength $\left(r_{Z}\right)$ and $(\mathrm{d}-\mathrm{f})$ slope $(b)$ of the latitudinal gradient of diversity separated for local $(\Delta)$ and regional $(\bullet)$ data sets. Effect sizes are given for $(a, d)$ different oceans (Pac: Pacific; Atl: Atlantic; Ind: Indian; ww: worldwide studies), (b,e) different hemispheres $(\mathrm{N}=$ northern and $\mathrm{S}=$ southern hemisphere), and (c,f) different latitudinal ranges. For the latter, range is the difference between maximum and minimum latitude observed

advancing more towards the poles had steeper slopes. Since the high polar diversity of the southern hemisphere was explicitly proposed as changing the structure of latitudinal gradients in the marine realm, I redid the analysis for each hemisphere separately, but this did not change the outcome: the maximum latitude investigated affected only the slope of the gradient and only at local scales, and it did so similarly at northern and southern latitudes. In contrast to minimum and maximum latitudes, the latitudinal range affected the slope significantly at both local and regional scales, and tended to affect regional gradient strength as well (Table 3). In all 3 cases, the relationship was negative (Table 4 ), i.e. data covering a wider range of latitudes revealed stronger and steeper latitudinal gradients (Fig. 2c,f).

\section{Habitats}

Regional and local gradient strength differed significantly or nearly significantly with different habitat types (Table 3). Significantly stronger regional gradients were found for the open ocean pelagial than for the coastal benthos (Fig. 3a). Generally, pelagic gradients tended to be stronger than benthic gradients. Weakest gradients were found for local host-specific organisms, whereas this pattern was not found for the equivalent regional data. The habitat-wise local gradient strength differed significantly between coastal and deep-sea benthos, the latter revealing stronger gradients. Regarding slopes, no significant effect of habitat types was found (Table 3). However, an interesting contrast to the results on gradient strength was that 
Table 4. Regression parameters for weighted meta-analysis with a continuous model. Independent variables were latitudinal range and body size, dependent variables were the weighted effect sizes strength $\left(r_{Z}\right)$ and slope $(b)$. The slope and intercept of the regression are given with standard errors for regional and local diversity estimates

\begin{tabular}{|lcllcrc|}
\hline \multirow{2}{*}{ Variable } & \multirow{2}{*}{ Effect size } & Scale & Slope & SE & Intercept & SE \\
\hline \multirow{2}{*}{ Range } & \multirow{2}{*}{$r_{Z}$} & Regional & -0.009 & 0.003 & -0.584 & 0.207 \\
& & Local & -0.013 & 0.002 & 0.154 & 0.107 \\
& \multirow{2}{*}{$b$} & Regional & 0.0003 & 0.004 & -1.434 & 0.240 \\
& & Local & -0.007 & 0.002 & 0.182 & 0.081 \\
Body size & \multirow{2}{*}{$r_{Z}$} & Regional & -0.085 & 0.029 & -1.199 & 0.071 \\
& \multirow{2}{*}{$b$} & Local & -0.041 & 0.096 & -0.561 & 0.096 \\
& & Regional & -0.211 & 0.028 & -1.544 & 0.069 \\
& & Local & -0.018 & 0.025 & -0.228 & 0.115 \\
\hline
\end{tabular}

steepest gradients pertained to the neritic pelagial (compared to oceanic) and coastal benthos (compared to deep sea) (Fig. 3b). Slope and strength of the gradient were significantly negative in the regional data set irrespective of the habitat type (Fig. 3a,b).

\section{Organisms}

The organismal characteristic most strongly affecting gradient strength or slope was body mass (Table 3, Fig. 4). For regional scales, there was a consistent negative relationship between

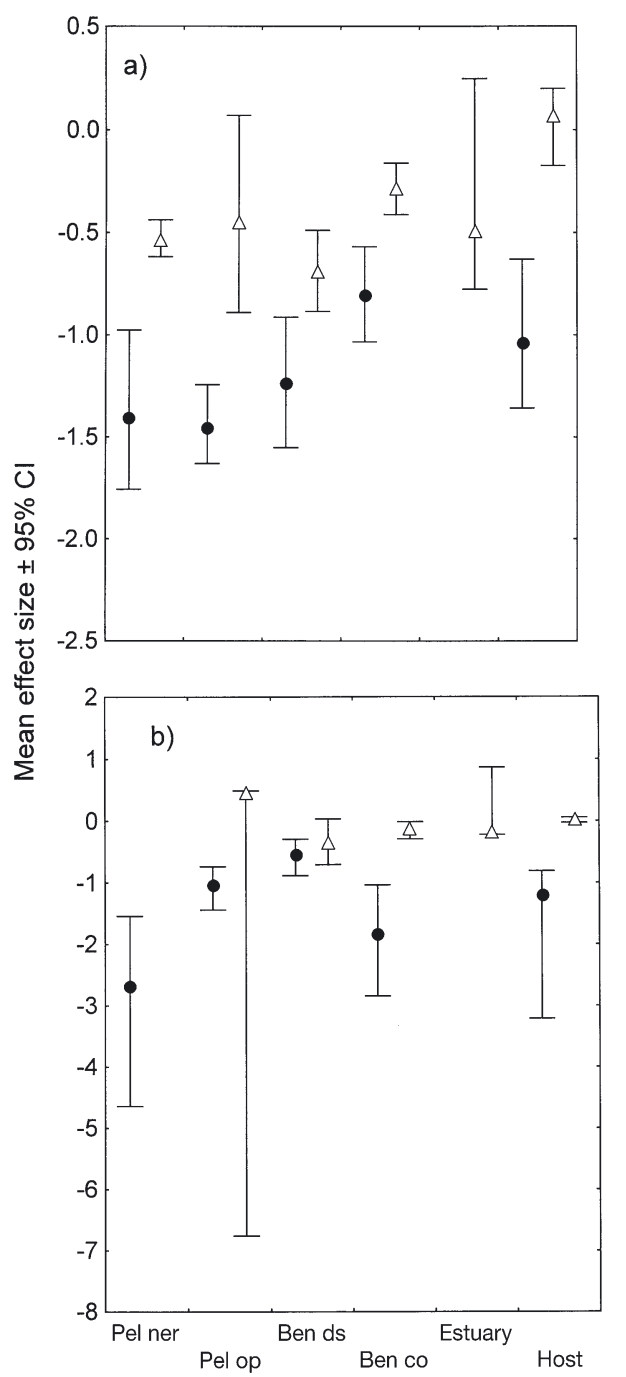

Fig. 3. Mean effect sizes $( \pm 95 \%$ confidence intervals, CI) for (a) strength $\left(r_{Z}\right)$ and (b) slope (b) of the latitudinal gradient of diversity separated for local $(\Delta)$ and regional $(\bullet)$ data sets. Effect sizes are given for different habitats (Pel ner: pelagic neritic; Pel op: pelagic open ocean; Ben ds: benthic deep sea; Benthic co: benthic coastal; Estuary; and Host) body mass and the effect size for both $r_{Z}$ and $b$ (Tables 3 $\& 4)$. Strongest and steepest gradients were confined to large organisms whereas small organisms showed weak and flat gradients (Fig. 4). The impact of body mass was significant for regional gradient strength and regional slope (Table 3). The slopes of the continuous metaanalysis model were consistently negative, even for the non-significant regression on local effect sizes (Table 4).

Only gradient strength significantly varied with other broad organismal traits. The trophic position affected regional gradient strength. Although the effect was marginally non-significant (Table 3), there was a conspicuous trend of increasing gradient strength with increasing trophic level: autotrophs showed weak gradients not significantly different from zero, whereas there was a tendency towards stronger gradients with increasing trophic position, and strongest gradients pertained to omnivores and carnivores (Fig. 5a). At the local scale, gradients were also weakest for autotrophs, and strongest for carnivores. Parasites had weak local gradients but strong regional gradients, which remained a consistent pattern for other organismal traits (Fig. 5b,c). The life form also affected gradient strength at both spatial scales (Table 3). Except for weak regional gradients in the few studies on pelagic seabirds (flying, Fig. 5b), the difference between life forms was mainly due to weak gradients in sessile organisms and infauna. These groups showed the weakest relationship to latitude at both spatial scales, whereas nekton, plankton and mobile epifauna showed steeper gradients (Fig. 5b).

Dispersal types did not affect gradient strength significantly (Table 3), but the group-wise average effects reflect some of the patterns seen before: weak gradients were related to flying organisms and to autotrophic organisms dispersing via seeds. For the other ported adults, pelagic larvae), the regional gradient strengths were very similar and always significantly dispersal models (mobile adults, passively trans- 

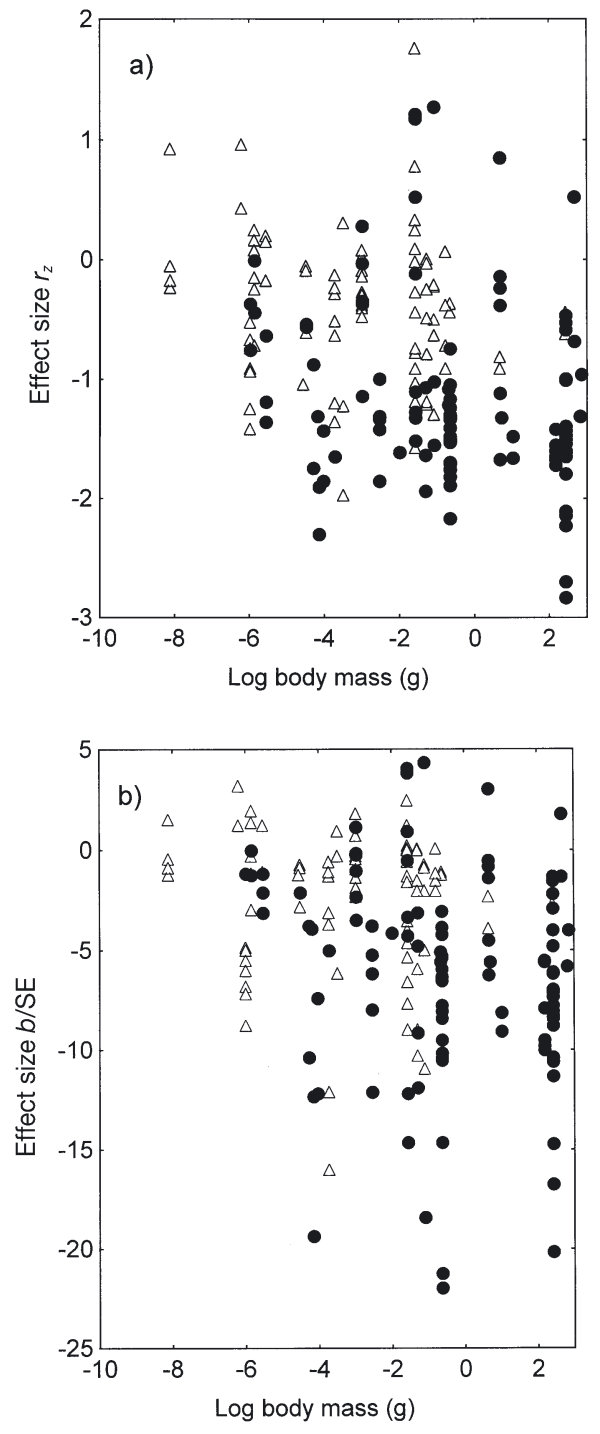

Fig. 4. Effect sizes for (a) strength $\left(r_{Z}\right)$ and (b) slope $(b)$ of the latitudinal gradient of diversity related to organismal body mass and separated for local $(\Delta)$ and regional $(\bullet)$ data sets

different from zero (Fig. 5c). None of the 3 classification variables (dispersal type, living mode and trophic position) had significant impacts on the slope of the gradient (Table 3).

The 'functional' group (organismal group) of organisms significantly affected regional and local gradient strength (Table 3). Putting the 'functional' types in size order from microalgae to fish (Fig. 6a) reveals that the increase in regional gradient strength with body mass is reflected by weak gradients for microalgae, protists, meiofauna and colonial zoobenthos (such as bryozoa) and strong gradients for arthropod and molluscan zoobenthos as well as fish. In between, there is a strong deviation from the body mass trends for marine macrophytes and zooplankton. The non-significance of ma-
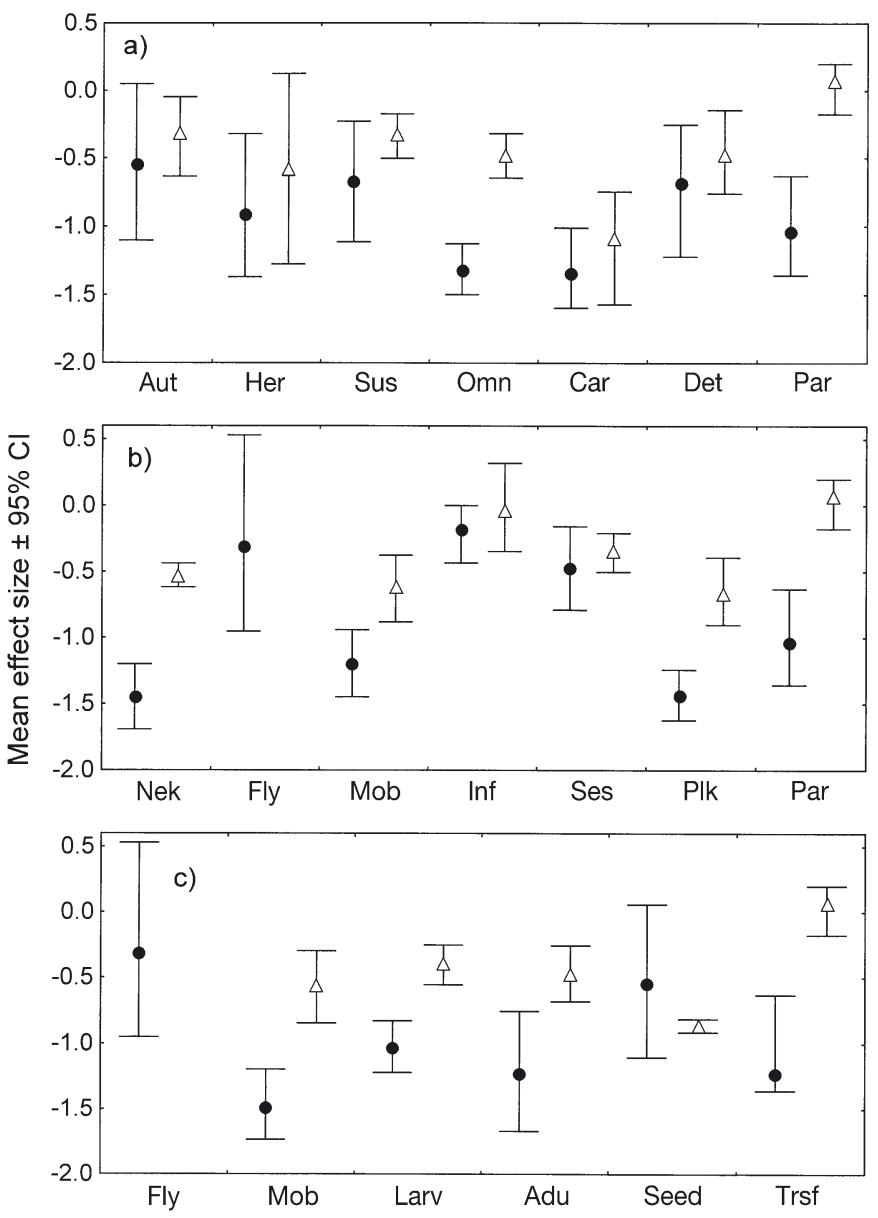

Fig. 5. Mean effect sizes $( \pm 95 \%$ confidence intervals, CI) for strength $\left(r_{Z}\right)$ of the latitudinal gradient of diversity separated local $(\Delta)$ and regional $(\bullet)$ data sets. Effect sizes are given for (a) different trophic levels (Aut: autotrophic; Her: herbivores; Sus: suspension feeder; Omn: omnivores; Car: carnivores; Det: detritivores and microbivores; Par: parasites), (b) different living modes (Nek: nekton; Fly: flying seabirds; Mob: mobile epifauna; Inf: infauna; Ses: sessile epifauna; Plk: plankton; Par: parasites), and (c) different dispersal modes (Fly: flying; Mob: mobile adults; Larv: pelagic passive larvae; Adu: passively transported adults; Seed: seeds or spores; Trsf: transfer)

rine macrophyte gradients reflects the data on trophic position (cf. autotrophs, Fig. 5a). Zooplankton exhibited very strong gradients, which may drive the pattern of strong pelagic gradients observed previously. Phlyogenetic differentiation is also represented by different gradient strengths (Table 3). Strongest gradients were revealed for Arthropoda and Chordata (which contain the largest individuals) and for predatory Chaetognatha. Weak regional gradients were observed for Nemathelminthes and Porifera. On a very coarse level, there was an increase in gradient strength with more recent phylogeny (Fig. 6b). Despite the significant variation in gradient strength with organismal group, it 


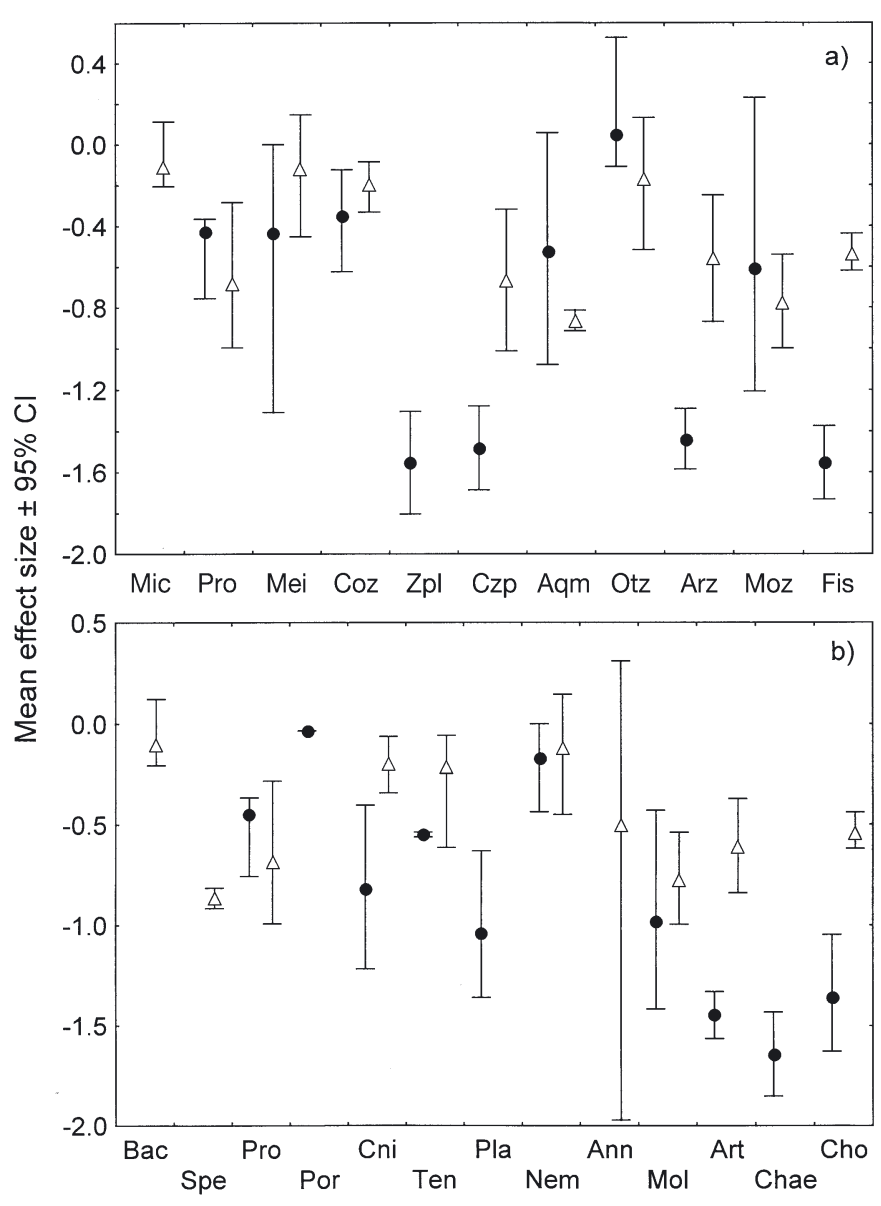

Fig. 6. Mean effect sizes $( \pm 95 \%$ confidence intervals, CI) for strength $\left(r_{Z}\right)$ of the latitudinal gradient of diversity separated for local $(\Delta)$ and regional $(\bullet)$ data sets. Effect sizes are given for (a) different functional organismal types (Mic: microalgae; Pro: protists; Mei: meiofauna; Coz: colonial zoobenthos; Zpl: other zooplankton; Czp: crustacean zooplankton; Aqm: aquatic macrophytes; Otz: other zoobenthos; Arz: arthropod zoobenthos; Moz: molluscan zoobenthos; Fis: fish), and (b) different phyla (Bac: Bacillariophyta; Spe: Spermatophyta; Pro: Protozoa; Por: Porifera; Cni: Cnidaria; Ten: Tentatulata; Pla: Plathelminthes; Nem: Nemathelminthes; Ann: Annelida; Mol: Mollusca; Art: Arthropods; Chae: Chaetognatha; Cho: Chordata)

should be noted that almost all types of organisms revealed average latitudinal gradients which were significantly negative at the regional scale. The only consistent exceptions were aquatic macrophytes and the group of other zoobenthos. The slope of the gradient was not affected by either functional or phylogenetic classification of organisms.

\section{DISCUSSION}

Using meta-analysis to analyse the strength and slope of the latitudinal gradient in diversity revealed that marine biota on average show a significant latitudinal gradient (corroborating hypothesis 1). The strength and slope of the marine gradients were of similar magnitude to those of gradients for terrestrial biota (partly supporting hypothesis 2), and both these groups had stronger and steeper gradients than freshwater organisms (partly refuting hypothesis 2). Latitudinal gradients differed significantly in different marine regions, habitat types and for different organisms (supporting hypothesis 3). Here, I discuss these results by (1) addressing the generality of marine diversity gradients, (2) comparing the pattern found in the meta-analysis to previous single studies, and (3) outlining the consequences of these findings for different underlying causes of the latitudinal gradient.

\section{The generality of marine latitudinal gradients}

In contrast to freshwater, marine gradients were as strong as or even stronger than terrestrial gradients. Moreover, marine latitudinal diversity declines were significant at both regional ( $\gamma$-diversity) and local scales ( $\alpha$-diversity). Only a decade ago, Clarke (1992) asked whether latitudinal gradients are less common in the sea than elsewhere. Several marine organisms are characterised by weak gradients due to low body mass (diatoms, protozoa), organism type (macrophytes) and life form (infauna). Despite the lack of significant gradients in these and other marine organisms and habitats, the first main conclusion from this analysis is that there is a significant average trend of decreasing marine diversity with increasing latitude. This conclusion is based on a large database, covering all world oceans, many kinds of habitats and organisms spanning almost 10 orders of magnitude in body mass. Although meta-analyses generally can be biased by selective publication of significant results (Blenckner \& Hillebrand 2002, Kotiaho \& Tomkins 2002), the present database contains more than one-third of nonsignificant gradients, which indicates that such bias has been avoided in this case. The original data (Hillebrand 2004) reflect strong differences in sampling effort, taxonomic resolution and definition of target organism groups. However, this does not affect the general conclusion of a significant average latitudinal decline in marine diversity. Meta-analysis techniques take sampling effort into account (see 'Materials and methods'). The gradient was moreover significantly negative for most pre-defined groups, at least for regional diversity (Figs. 2-6), which indicates that the gradient is not restricted to certain organismal groups, geographic regions or habitats.

The gradient of decreasing diversity with increasing latitude is thus without doubt one of the most general 
patterns of species distribution. It can be found for all kinds of organisms and habitats (Rohde 1978, 1992, this study), and even for other biological attributes such as human languages (Mace \& Pagel 1995, Moore et al. 2002). Besides, it is also a very old spatial pattern and already present in fossil diversity varying with paleolatitude (Stehli et al. 1969, Raymond et al. 1989).

The overall significant trend does not mean that gradients are invariant. In contrast, the high proportion of non-significant gradients and the significant effect of several variables on the gradient parameter strength and slope showed that latitudinal gradients are variable across scales, habitats and organisms. Moreover, latitudinal gradients are crude abstractions in one dimension, since they do not reflect longitudinal or bathymetrical variation in diversity. The presence of strong latitudinal gradients in the marine realm does not preclude the existence of more complex patterns of diversity in 3D space (see 'Introduction'). Still, the decline of marine diversity with latitude is obviously a consistent aspect of marine diversity and requires investigation of (1) the factors influencing the shape of the gradient and (2) the primary causes of the gradient.

\section{The shape of marine latitudinal gradients}

The differences in gradient strength and slope between regional and local data sets were the most obvious patterns found for both slope and strength. Similar results were obtained in a general analysis of gradients in all realms (Hillebrand 2004), with stronger and steeper gradients found on regional scales. This difference between scales of diversity assessment was not due to systematic errors such as higher autocorrelation of diversity estimates on regional scales (Hillebrand 2004). Latitudinal gradients are thus clearly a regional phenomenon, although the gradients are still significant at local scales. The latitudinal gradients mainly reflect the fact that the maximum number of species (regional richness) declines with latitude, and to a lesser extent the number of locally coexisting species. This also indicates that species turnover ( $\beta$-diversity) increases towards the tropics (Stevens \& Willig 2002).

In addition to scale, body mass was a second important factor influencing the strength and slope of the latitudinal gradient. The importance of body mass had previously been shown with a much smaller database (Hillebrand \& Azovsky 2001) and is also present over the entire data set (Hillebrand 2004). In addition to the direct impact of body mass on both slope and strength, differences found with other variables (organismal group, dispersal mode) were also partly related to body mass.
Despite the consistent impact of body mass, it is unlikely that body mass per se affects the latitudinal gradient. None of the proposed hypotheses for the latitudinal gradient (see below) predicts a consistently different relationship between the underlying factor and organismal groups of different mass. Before discussing the probable effect of body mass on gradient structure, 2 points have to be noted with respect to body mass. First, substantial variation is evident in the relationship between body mass and gradient strength and slope, respectively. Evidently, the body mass impact on the gradient is important only over a wide range of sizes. Some variation in the body mass gradient can be explained by the impact of organismal groups with extraordinarily weak (macrophytes) or strong gradients (Chaetognatha) (see below for more details). Second, the impact of body mass on the latitudinal gradient is not equivalent to studies relating latitude and body mass (Gillooly \& Dodson 2000, Roy et al. 2000a). Whereas the latter studies investigated changes in body mass with latitude within a certain organismal group, the present analysis analysed the variation in the shape of the gradient between organismal groups of different size.

The effect of body mass may be related to dispersal chance, energetic constraints and/or population size (Hillebrand 2004). Dispersal chance depends on passive transport and active mobility. The chance of passive transport depends on large-scale currents and is proposed to increase with decreasing body mass due to high individual number (= high number of propagules), short generation times and high transportability (Fenchel 1993, Fenchel et al. 1997, Finlay et al. 1997). The notion of ubiquitous dispersal of eukaryotic microbes has been proposed by ecologists (Fenchel 1993, Finlay et al. 1996), but criticised by taxonomists (Mann \& Droop 1996, Foissner 1999, Sabbe et al. 2001). Recent tests of the proposed ubiquity using the distribution of protists (Finlay et al. 2001, Hillebrand et al. 2001) revealed that microbial organisms are-if not ubiquitous - at least widely dispersed. For meiofauna, equivocal results on latitudinal gradients have been obtained (Boucher 1990, Lambshead et al. 2000, 2001, 2002, Mokievsky \& Azovsky 2002), whereas the weakness of large-scale diversity patterns for smallest organisms has repeatedly been shown (Finlay et al. 1999, 2001, Hillebrand \& Azovsky 2001). This weakness does not necessarily imply a complete lack of biogeography (Smith 1982, Dolan 2000, Wilkinson 2001), but it implies a less important role of restricted distribution for unicellular eukaryotes compared to larger organisms. The weak biogeography is also not simply due to biased taxonomic knowledge, since restricting data to a single taxonomic source still resulted in weak regional pat- 
terns of species distribution (Hillebrand et al. 2001). Some studies even suggested a boundary size delimiting ubiquitous and restricted distribution, either $2 \mathrm{~mm}$ (Finlay 2002) or $100 \mu \mathrm{m}$ (Wilkinson 2001), but the results discussed above render it rather improbable that such a threshold size exists on a general level. Moreover, the overall dispersal chance may be related to body mass in a non-linear fashion. The passive component of dispersal is overall negatively correlated to body size (larger organisms with less dispersal chance), but large organisms may be more able to migrate actively.

The regional increase in gradient strength with trophic level corresponds well to the overall picture from marine, terrestrial and freshwater habitats (Hillebrand 2004). That marine data show the same overall trend is not due to a simple body mass effect, since autotrophs include microalgae as well as macroalgae and aquatic vascular plants, and carnivores include chaetognaths as well as many fish. Single studies on macrophytes found either no significant gradient at all (Bolton 1994), or significant gradients in the Atlantic, whereas macroalgal diversity in the Pacific did not decline (Gaines \& Lubchenco 1981) and even increased (Santelices \& Marquet 1998) towards the poles. A possible reason for rather low tropical macrophyte diversity might be the competition for space with corals (Bolton 1994).

Parasites exhibited weak local gradients, whereas regional parasitic gradients were strong (Fig. 5a) and comparable to their host organisms. The reason for the weak local gradients is not entirely clear, but local parasite surveys may have a high risk of undersampling rare species.

Among life forms, the strength of the gradient varied significantly in the meta-analysis, and except for parasites, weak local as well as regional gradients were confined to sessile epifaunal and infaunal organisms. The absence of a latitudinal gradient for endobenthic marine fauna was postulated quite early (Thorson 1952, 1957), and later named 'Thorson's rule'. Later studies found significant gradients also for sedimentdwelling macrozoobenthos (Roy et al. 2000b, Gray 2002 for the northern hemisphere), but my analysis shows that infaunal gradients tend to be generally weak. The possible reasons for the weakness of endobenthos and sessile epibenthos are not straightforward. Thorson's $(1952,1957)$ original argument was that infauna are protected from temporal environmental fluctuations and experience a spatially rather homogeneous habitat, but heterogeneity is no longer proposed as a major reason for gradients (Roy et al. 2000b, see also below).

Species richness varies not only across latitude but also across longitude. The pattern is less regular, but has been known for as long as the latitudinal gradient (Humboldt 1828). The implications of longitudinal differences became evident in the variation of gradient strength in different oceans found in the metaanalysis. The different geological background of different oceans (Poore \& Wilson 1993) has been evoked to explain their different species richness. Although the Pacific Ocean is older than the Atlantic, the present analysis revealed weaker gradients for the Pacific at regional scales. The Indian Ocean was represented in the least studies and its latitudinal extent is smallest. An interesting pattern, however, emerged: the slope of the gradient was very steep in the Indian Ocean, whereas the strength was weak. This pattern corresponds to the notion that biodiversity hotspots dominate the spatial pattern of diversity in the Indian Ocean, from which diversity radially decreases (Hughes et al. 2002). High overall richness and radial rather than latitudinal gradients correspond well to the steep slope and the weak strength of the latitudinal gradient.

Several authors suggested that latitudinal patterns should be different between hemispheres, both for land-living organisms (Blackburn \& Gaston 1996, Gaston \& Williams 1996) and in the sea (Culver \& Buzas 2000, Gray 2001a,b, 2002). Proposed reasons comprise different land-to-sea ratios in area between the hemispheres and the high marine diversity in the Antarctic compared to the Arctic (Brey et al. 1994, Gray 2001a). Although hemispheric differences in diversity patterns were described for some groups, this difference was clearly not general. Northern and southern hemispheres harbour latitudinal gradients of similar average strength and slope in the marine realm. To accommodate concerns on the poor quality of older polar diversity assessments in the literature, I re-analysed the difference between hemispheres with data published during the last decade (1993 to 2003). This restriction did not change the outcome: slope and strength of the gradient were not significantly different between northern and southern hemispheres. Moreover, the proposed high Antarctic diversity did not change the strength of the gradients in studies including polar seas: increasing maximum latitude included in the original study did not reduce gradient strength and slope as would be expected from high diversity near the Antarctic. Clearly, these results do not negate the existence of higher diversity of certain organismal groups at southern rather than northern polar latitudes, which has been documented widely (Brey et al. 1994, Gray 2001a,b, 2002). Even though these differences between the poles exist, they do not result in an overall changed structure of the latitudinal gradient across all groups. This pattern may change with more detailed knowledge on polar diversity. More data are 
necessary to address the questions for which groups polar diversity in the southern hemisphere is high and how this affects the global diversity trend.

In contrast to the maximum and minimum values of latitude, the latitudinal range over which diversity was assessed strongly affected the slope and also gradient strength. A more complete coverage of the latitudinal range obviously decreased slope and correlation coefficients, i.e. resulted in steeper and stronger gradients. Whereas this pattern was significant in the marine data set, it did not emerge in the general analysis including terrestrial and freshwater data (Hillebrand 2004). Thus, extending the analysis poleward or close to the equator is highly recommended for future assessments of latitudinal gradients.

Different large marine habitats differed rather weakly in their gradient strength and slope and, at a regional scale, all habitats revealed significant diversity clines with latitude. Again, the similarity of the gradient strength is more surprising than the significant differences. However, some distinctions in gradient strength were observed. In particular, the gradients in the pelagic environment were as strong as or even stronger than in benthic habitats, although large-scale currents are possibly able to blur biogeographic patterns in the pelagial. However, the openness may be less than expected, since large-scale current systems can confine marine fauna to certain regions (Williams et al. 2001, see also below). The importance of regional oceanography for the connection and separation of marine organisms is a highly underdeveloped area of research on marine biodiversity. The unexpectedly strong pelagic gradients may be based on the organismal subsets (weak macrophyte gradients always being benthic, strong fish gradients rather being pelagic).

Although the slope of the latitudinal diversity cline was less steep in deep seas compared to coastal benthos (cf. Fig. 3b), the gradient strength was stronger in the deep sea than in the coastal benthos. Bearing the speciality of the different habitats in mind, the similarity is more stunning than the difference. Much research has been devoted to exploring the diversity of the deep sea, which clearly is extraordinary in many aspects (Hessler \& Sanders 1967, Sanders 1968, Haedrich 1985, Grassle \& Maciolek 1992, Rex et al. 1993, Wilson 1998, Lambshead et al. 2000, Richer De Forges et al. 2000, Gray 2002). However, with respect to the latitudinal gradient structure, deep-sea benthos is not special compared to other marine habitats. Rex et al. (2000) also found strong similarity between deepsea and shallow-water latitudinal gradients for gastropod species richness. This observation does not preclude the existence of trends in latitudinal gradients with bathymetry, which however could not be resolved in this analysis.

\section{Underlying causes of the latitudinal gradient}

The generality of any possible explanation for the latitudinal gradient has been a long-standing debate. The search for a primary cause of the latitudinal gradient has led to a rather unsubstantiated discussion on whether there is one central cause (Rohde 1992, Pianka 2000) or if many causes covary (Kaufman 1995, Gaston 2000, Macpherson 2002) to produce the pattern observed. In contrast to the discussion on the generality of the explanations for the gradient, it has been well accepted that the exceptional reversed gradients (such as macroalgae) are based on non-general local interactions or group characteristics (Clarke 1992, Bolton 1994). The generality of a meta-analysis can provide information on the suitability of different models often used to explain the latitudinal gradient.

Mid-domain models predict the highest species richness in the middle of a range defined by hard boundaries without involving ecological or evolutionary forces. Defining earth as a domain with the poles as hard boundaries, mid-domain models predict higher tropical diversity simply from a higher chance of species ranges overlapping in the centre of the domain (Colwell \& Hurtt 1994). Subsequent evidence was found for global gradients (Colwell \& Hurtt 1994, Lyons \& Willig 1997, Willig \& Lyons 1998, Jetz \& Rahbek 2001, Koleff \& Gaston 2001), regional gradients (Lees et al. 1999), and even altitudinal gradients (Rahbek 1997). The consistency of the latitudinal gradient across all habitats and biota actually sustained the impression of a general, non-biological trend. The mid-domain model is a null model, and ecological and evolutionary forces may result in deviations, which are reflected by the structure in the slopes and strengths of latitudinal gradients observed here. Random placement of geographic boundaries according to middomain models may set a general tendency towards higher tropical species richness, but the strength and slope of the gradient are affected by the type of organism, life form, trophic position, body weight, habitat type, and geographic position.

Gradients in energy (or a surrogate for energy) and area covary with latitude and have been proposed as ultimate causes of the latitudinal gradient. A longstanding debate has been fuelled about whether energy or area gradients are fundamental for the latitudinal diversity gradient. Following suggestions on the large area of the tropics (Terborgh 1973), the area hypothesis was mainly proposed by Rosenzweig (1992, 1995), and defended (Rosenzweig \& Sandlin 1997) against notions that area per se cannot explain species richness patterns due to low species richness in large biomes such as some oceanic habitats (Rohde 1997, 1998). Some studies revealed positive correlations 
between regional area and species richness (Blackburn \& Gaston 1997, Ruggiero 1999). However, other studies falsified this pattern, stating that neither were tropical biomes larger nor was richness related to area at biome scales (Hawkins \& Porter 2001). A common notion in several contributions on the area hypothesis, however, is that productivity may influence the importance of area as a factor determining latitudinal gradients (Rohde 1997, 1998, Rosenzweig \& Sandlin 1997, Chown \& Gaston 2000). At the same time, favouring productivity (energy) as a primary cause, the impact of scale on the species-energy hypothesis is acknowledged (Currie 1991). The scale dependence of the energy hypothesis is also clearly related to the scale dependence of the productivity- diversity relationship (Waide et al. 1999, Mittelbach et al. 2001, Rajaniemi 2003), suggesting a rather unimodal response of diversity to productivity at local scales and linear at regional scales (Chase \& Leibold 2002). Thus, area and energy may be interconnected variables with respect to diversity gradients (Gaston \& Blackburn 2000).

The species energy hypothesis was proposed by Wright (1983) and has received much supporting evidence (Currie 1991, Fraser \& Currie 1996), especially in marine environments (Roy et al. 1998, Rutherford et al. 1999). However, the high evidential support may also be based on the high number of surrogate parameters used for energy, which comprise air temperature, sea temperature (Rutherford et al. 1999, Roy et al. 2000b), irradiance (Roy et al. 1998), biomass (Fraser \& Currie 1996), productivity (Woodd-Walker et al. 2002), actual evapotranspiration (Currie 1991) and potential evapotranspiration (Currie 1991). The major drawback of the energy hypothesis, however, is that it does not present the mechanistic link transferring higher energy into higher diversity (Huston 1999). Energy input may explain how much biomass can be built up, but not how this is distributed over several species (Gaston \& Blackburn 2000, Hurlbert \& Haskell 2003). A recent model based on the energy equivalence rule related temperature effects on biochemical kinetics to species richness (Allen et al. 2002). This proposal is still under discussion (Allen et al. 2003, Storch 2003), but points at a possible mechanism whereby increasing process rates with temperature result in increasing net diversification. Such a relationship between climate and speciation has long been postulated, stating that energy in general, and temperature in particular, have consistent consequences for generation times and mutation rates (Rensch 1954). The proposition has recently been tested, finding indeed increased diversification rates for butterflies and birds at low latitudes (Cardillo 1999).

The effective evolutionary time model invokes speciation as a major process regulating the latitudinal gra- dient of diversity (Rohde 1992, Stephens \& Wiens 2003), but relates the higher speciation in the tropics to gradients similar to those used in the environmental gradient model (area, energy, variability). The differentiation between the 2 models (environmental gradient vs effective evolutionary time) is difficult due to the scarce information from fossil data. However, those studies allowing a comparison of fossil and recent diversity gradients indicate higher net diversification in the tropics than in temperate areas (Buzas et al. 2002). Moreover, there is increasing evidence that the tropics are major centres of evolutionary novelty (Crane \& Lidgard 1989, Jablonski 1993). Also in marine habitats, faunas in the tropics evolved faster than in temperate areas (Stehli et al. 1969). In bivalves, the latitudinal gradients decrease with age of the clades, showing that species evolving in the tropics slowly radiate into neighbouring biomes (Crame 2000). Similarly, foraminiferan species richness in tropical waters was based on rare species without fossil records, i.e. species from recent diversification and with endemic distribution (Buzas \& Culver 1999).

Higher speciation rates in the tropics can only be a cause of the marine latitudinal gradient if large-scale dispersal or migration does not lead to fast spreading of organisms across latitudes. The importance of dispersal limitation has been stressed in recent years in order to explain community assembly and species composition in terrestrial habitats (Zobel 1997, Hubbell et al. 1999, Zobel et al. 2000, Hubbell 2001). Marine systems have traditionally been viewed as rather open systems with high dispersal rates. Nonetheless, there is increasing evidence (at least in some marine systems) that large-scale dispersal is less common than previously hypothesised (Jones et al. 1999, Swearer et al. 1999, Cowen et al. 2000, Marsh et al. 2001). Cowen et al. (2000) found strong evidence for the prevalence of short distance dispersal in marine systems. Jones et al. (1999) showed high importance of self-recruitment in coral reef fish populations, although this may not be directly related to confinement or ranges: Victor \& Wellington (2000) showed that pelagic larval duration was not consistently related to distribution range in reef fishes. However, the main hypothesis emerging from these studies is that a continuum from very open to almost enclosed marine locations can be found, determined by oceanographic factors, life history, and propagule features. Therefore, even on large evolutionary time scales, most organisms do not extend their distribution easily (Rohde 1998).

Least general of all explanatory models are those involving ecological interactions (Jeanne 1979). Ecological interactions are clearly able to structure local diversity, especially the interaction of consumption and 
resource competition (Huston 1979, Worm et al. 2002). However, in order to contribute to the latitudinal gradient, the interactions have to vary systematically with latitude. Such consistent change in ecological interactions with latitude has received some support (Möller 1998, Pennings et al. 2001). Also in marine habitats, evidence was found for latitudinal gradients in ecological interactions, but the changes in the sign of the ecological interactions were not consistent. Different harshness of conditions may shift interactions between macrophytes from being competitive in benign northern climates towards being mutualistic in harsh (heatstressed, tropic) climates (Bertness \& Ewanchuk 2002). Competitive interactions may increase at higher latitudes of the northeastern Pacific due to higher larval supply (Connolly \& Roughgarden 1998). A latitudinal trend towards higher plant palatability was found for salt-marsh plants offered to herbivores (Pennings et al. 2001). Except for the inconsistencies of stronger or weaker interactions at higher latitudes, many studies falsified the proposition of interactions being more specific (Beaver 1979, Ollerton \& Cranmer 2002), more intense (Hubbell 1980), or more density-dependent (Lambers et al. 2002) in the tropics. In my analysis, the model is additionally falsified by the higher generality of the gradient at regional scales. Thus, while latitudinal differences in ecological interactions exist, they are unlikely to be the ultimate cause of the gradient. However, the existing difference between regional and local gradients of diversity indicates the importance of ecological interactions in modifying the gradient at small scales.

Acknowledgements. I thank Andrea Belgrano for organising the stimulating session on 'Emergent properties' at the ASLO conference in Salt Lake City, Utah. The manuscript profited from comments by Stefanie Moorthi, Andrea Belgrano and 4 anonymous reviewers. Financial support was provided by the Swedish National Research Council (Vetenskapsrådet, 621-2002-215) and the Institute for Marine Research Kiel.

\section{LITERATURE CITED}

Allen AP, Brown JH, Gillooly JF (2002) Global biodiversity, biochemical kinetics, and the energy-equivalence rule. Science 297:1545-1548

Allen AP, Brown JH, Gillooly JF (2003) Reply to comment on 'Global biodiversity, biochemical kinetics, and the energyequivalence rule'. Science 299:346

Barnes DKA, Arnold R (2001) A growth cline in encrusting benthos along a latitudinal gradient within Antarctic waters. Mar Ecol Prog Ser 210:85-91

Beaver RA (1979) Host specifity of temperate and tropical animals. Nature 281:139-141

Bertness MD, Ewanchuk PJ (2002) Latitudinal and climatedriven variation in the strength and nature of biological interactions in New England salt marshes. Oecologia 132: 392-401

Blackburn TM, Gaston KJ (1996) Spatial patterns in the spe- cies richness of birds in the New World. Ecography 19: 369-376

Blackburn TM, Gaston KJ (1997) The relationship between geographic area and the latitudinal gradient in species richness in New World birds. Evol Ecol 11:195-204

Blenckner T, Hillebrand H (2002) North Atlantic Oscillation signatures in aquatic and terrestrial ecosystems - a metaanalysis. Global Change Biol 8:203-212

Bolton JJ (1994) Global seaweed diversity: patterns and anomalies. Bot Mar 37:241-245

Boucher G (1990) Patterns of nematode species diversity in temperate and tropical subtidal sediments. PSZN I: Mar Ecol 11:133-146

Brey T, Klages M, Dahm C, Gorny M and 6 others (1994) Antarctic benthic diversity. Nature 368:297

Buzas MA, Culver SJ (1999) Understanding regional species diversity through the log series distribution of occurrences. Divers Distrib 8:187-195

Buzas MA, Collins LS, Culver SJ (2002) Latitudinal difference in biodiversity caused by higher tropical rate of increase. Proc Natl Acad Sci USA 99:7841-7843

Cardillo M (1999) Latitude and rates of diversification in birds and butterflies. Proc R Soc Lond B Biol Sci 266:1221-1225

Chase JM, Leibold MA (2002) Spatial scale dictates the productivity-biodiversity relationship. Nature 416:427-430

Chown SL, Gaston KJ (2000) Areas, cradles and museums: the latitudinal gradient in species richness. Trends Ecol Evol 15:311-315

Clarke A (1992) Is there a latitudinal diversity cline in the sea? Trends Ecol Evol 7:286-287

Colwell RK, Hurtt GC (1994) Nonbiological gradients in species richness and a spurious Rapoport effect. Am Nat 144: 570-595

Connolly SR, Roughgarden J (1998) A latitudinal gradient in northeast Pacific intertidal community structure: evidence for an oceanographically based synthesis of marine community theory. Am Nat 151:311-326

Cowen RK, Lwiza KMM, Sponaugle S, Paris CB, Olson DB (2000) Connectivity of marine populations: open or closed. Science 287:857-859

Crame JA (2000) Evolution of taxonomic diversity gradients in the marine realm: evidence from the composition of recent bivalve faunas. Paleobiology 26:188-214

Crane PR, Lidgard S (1989) Angiosperm diversification and paleolatitudinal gradients in cretaceous floristic diversity. Science 246:675-678

Culver SJ, Buzas MA (2000) Global latitudinal species diversity gradient in deep-sea benthic foraminifera. Deep-Sea Res I 47:259-275

Currie DJ (1991) Energy and large-scale patterns of animaland plant-species richness. Am Nat 137:27-49

Currie DJ, Francis AP, Kerr JT (1999) Some general propositions about the study of spatial patterns of species richness. Ecoscience 6:392-399

Dolan JR (2000) Tintinnid ciliate diversity in the Mediterranean Sea: longitudinal patterns related to water column structure in late spring. Aquat Microb Ecol 22:69-78

Ellingsen KE, Gray JS (2002) Spatial patterns of benthic diversity: is there a latitudinal gradient along the Norwegian continental shelf? J Anim Ecol 71:373-389

Englund G, Sarnelle O, Cooper SD (1999) The importance of data-selection criteria: meta-analyses of stream predation experiments. Ecology 80:1132-1141

Fenchel T (1993) There are more small than large species? Oikos 68:375-378

Fenchel T, Esteban GF, Finlay BJ (1997) Local versus global diversity of microorganisms: cryptic diversity of ciliated 
protozoa. Oikos 80:220-225

Finlay BJ (2002) Global dispersal of free-living microbial eukaryote species. Science 296:1061-1063

Finlay BJ, Esteban GF, Fenchel T (1996) Global diversity and body size. Nature 383:132-133

Finlay BJ, Maberly SC, Cooper JI (1997) Microbial diversity and ecosystem function. Oikos 80:209-213

Finlay BJ, Esteban GF, Olmo JL, Tyler PA (1999) Global distribution of free-living microbial species. Ecography 22: 138-144

Finlay BJ, Esteban GF, Clarke KJ, Olmo JL (2001) Biodiversity of terrestrial protozoa appears homogeneous across local and global spatial scales. Protist 152:355-366

Fischer AG (1960) Latitudinal variation in organic diversity. Evolution 14:64-81

Foissner W (1999) Protist diversity: estimates of the nearimponderable. Protist 150:363-368

Fraser RH, Currie DJ (1996) The species richness-energy hypothesis in a system where historical factors are thought to prevail: coral reefs. Am Nat 148:138-159

Gaines SD, Lubchenco J (1981) A unified approach to marine plant-herbivore interactions. II. Biogeography. Annu Rev Ecol Syst 13:111-138

Gaston KJ (2000) Global patterns in biodiversity. Nature 405: $220-227$

Gaston KJ, Blackburn TM (2000) Pattern and process in macroecology. Blackwell Scientific Publications, Oxford

Gaston KJ, Williams PH (1996) Spatial patterns in taxonomic diversity. In: Gaston K (ed) Biodiversity. Blackwell Scientific Publications, Oxford, p 202-229

Gillooly JF, Dodson SI (2000) Latitudinal patterns in the size distribution and seasonal dynamics of new world, freshwater cladocerans. Limnol Oceanogr 45:22-30

Grassle JF, Maciolek NJ (1992) Deep-sea species richness: regional and local diversity estimates from quantitative bottom samples. Am Nat 139:313-341

Gray JS (2001a) Antarctic marine benthic biodiversity in a world-wide latitudinal context. Polar Biol 24:633-641

Gray JS (2001b) Marine diversity: the paradigms in patterns of species richness. Sci Mar 65:41-56

Gray JS (2002) Species richness of marine soft sediments. Mar Ecol Prog Ser 244:285-297

Gurevitch J, Hedges LV (1993) Meta-analysis: combining the results of independent experiments. In: Scheiner SM, Gurevitch J (eds) Design and analysis of ecological experiments. Chapman \& Hall, New York, p 378-398

Gurevitch J, Hedges LV (1999) Statistical issues in ecological meta-analyses. Ecology 80:1142-1149

Haedrich RL (1985) Species number-area relationship in the deep sea. Mar Ecol Prog Ser 24:303-306

Hawkins BA (2001) Ecology's oldest pattern? Trends Ecol Evol 16:470

Hawkins BA, Porter EE (2001) Area and the latitudinal diversity gradient for terrestrial birds. Ecol Lett 4:595-601

Hessler RR, Sanders HL (1967) Faunal diversity in the deepsea. Deep-Sea Res 14:65-78

Hillebrand $\mathrm{H}$ (2004) On the generality of the latitudinal gradient of diversity. Am Nat 163:192-211

Hillebrand H, Azovsky AI (2001) Body size determines the strength of the latitudinal diversity gradient. Ecography 24:251-256

Hillebrand H, Blenckner T (2002) Regional and local impact on species diversity - from pattern to processes. Oecologia 132:479-491

Hillebrand H, Watermann F, Karez R, Berninger UG (2001) Differences in species richness patterns between unicellular and multicellular organisms. Oecologia 126:114-124
Hubbell SP (1980) Seed predation and the coexistence of tree species in tropical forests. Oikos 35:214-229

Hubbell SP (2001) The unified neutral theory of biodiversity and biogeography. Princeton University Press, Princeton, $\mathrm{NJ}$

Hubbell SP, Foster RB, O'Brien ST, Harms KE, Condit R, Wechsler B, Wright SJ, Loo de Lao S (1999) Light-gap disturbances, recruitment limitation, and tree diversity in a neotropical forest. Science 283:554-557

Hughes TP, Bellwood DR, Connolly SR (2002) Biodiversity hotspots, centres of endemicity, and the conservation of coral reefs. Ecol Lett 5:775-784

Humboldt Av (1828) Über das Universum-die Kosmosvorträge 1827/28 in der Berliner Singakademie. Edited from listener's notes, printed 1993 by Insel Verlag, Frankfurt

Hurlbert AH, Haskell JP (2003) The effect of energy and seasonality on Avian species richness. Am Nat 161:83-97

Huston M (1979) A general hypothesis of species diversity. Am Nat 113:81-101

Huston MA (1994) Biological diversity: the coexistence of species in changing landscapes. Cambridge University Press, Cambridge

Huston MA (1999) Local processes and regional patterns: appropriate scales for understanding variation in the diversity of plants and animals. Oikos 86:393-401

Jablonski D (1993) The tropics as a source of evolutionary novelty through geological time. Nature 364:142-144

Jeanne RL (1979) A latitudinal gradient in rates of ant predation. Ecology 60:1211-1224

Jetz W, Rahbek C (2001) Geometric constraints explain much of the species richness pattern in African birds. Proc Natl Acad Sci USA 98:5661-5666

Jones GP, Milicich MJ, Emslie MJ, Lunow C (1999) Selfrecruitment in a coral reef fish population. Nature 402 802-804

Kaufman DM (1995) Diversity of new world mammals: universality of the latitudinal gradients of species and bauplans. J Mammal 76:322-334

Koleff P, Gaston KJ (2001) Latitudinal gradients in diversity: real patterns and random models. Ecography 24:341-351

Kotiaho JS, Tomkins JL (2002) Meta-analysis, can it ever fail? Oikos 96:551-553

Lambers JHR, Clark JS, Beckage B (2002) Density-dependent mortality and the latitudinal gradient in species diversity. Nature 417:732-735

Lambshead PJD, Tietjen J, Ferrero T, Jensen P (2000) Latitudinal diversity gradients in the deep sea with special reference to North Atlantic nematodes. Mar Ecol Prog Ser 194:159-167

Lambshead PJD, Tietjen J, Moncrieff CB, Ferrero TJ (2001) North Atlantic latitudinal diversity patterns in deep-sea marine nematode data: a reply to Rex et al. Mar Ecol Prog Ser 210:299-301

Lambshead PJD, Brown CJ, Ferrero TJ, Mitchell NJ, Smith CR, Hawkins LE, Tietjen J (2002) Latitudinal diversity patterns of deep-sea marine nematodes and organic fluxes: a test from the central equatorial Pacific. Mar Ecol Prog Ser 236:129-135

Lees DC, Kremen C, Andriamampianina L (1999) A null model for species richness gradients: bounded range overlap of butterflies and other rainforest endemics in Madagascar. Biol J Linn Soc 67:529-584

Lyons SK, Willig MR (1997) Latitudinal patterns of range size: methodological concerns and empirical evaluations for New World bats and marsupials. Oikos 79:568-580

Mace R, Pagel M (1995) A latitudinal gradient in the density 
of human languages in North-America. Proc R Soc London B Biol Sci 261:117-121

Macpherson E (2002) Large-scale species-richness gradients in the Atlantic Ocean. Proc R Soc Lond B Biol Sci 269: 1715-1720

Mann DG, Droop SJM (1996) Biodiversity, biogeography and conservation of diatoms. Hydrobiologia 336:19-32

Marsh AG, Mullineaux LS, Young CM, Manahan DT (2001) Larval dispersal potential of the tubeworm Riftia pachyptila at deep-sea hydrothermal vents. Nature 411:77-80

Mittelbach GG, Steiner CF, Scheiner SM, Gross KL and 5 others (2001) What is the observed relationship between species richness and productivity? Ecology 82:2381-2396

Mokievsky V, Azovsky A (2002) Re-evaluation of species diversity patterns of free-living marine nematodes. Mar Ecol Prog Ser 238:101-108

Möller AP (1998) Evidence of larger impact of parasites on hosts in the tropics: investment in immune function within and outside the tropics. Oikos 82:265-270

Moore JL, Manne L, Brooks T, Burgess ND, Davies R, Rahbek C, Williams P, Balmford A (2002) The distribution of cultural and biological diversity in Africa. Proc R Soc Lond B Biol Sci 269:1645-1653

Ollerton J, Cranmer L (2002) Latitudinal trends in plant-pollinator interactions: are tropical plants more specialised? Oikos 98:340-350

Owen DF, Owen J (1974) Species diversity in temperate and tropical Ichneumonidae. Nature 249:583-584

Pennings SC, Siska EL, Bertness MD (2001) Latitudinal differences in plant palatability in Atlantic coast salt marshes. Ecology 82:1344-1359

Peters RH (1983) The ecological implications of body size. Cambridge University Press, Cambridge

Pianka ER (1966) Latitudinal gradients in species diversity: a review of concepts. Am Nat 100:33-46

Pianka ER (2000) Evolutionary ecology, 6th edn. Benjamin Cummings, San Francisco, CA

Poore GCB, Wilson GDF (1993) Marine species richness. Nature 361:597-598

Price ARG (2002) Simultaneous 'hotspots' and 'coldspots' of marine biodiversity and implications for global conservation. Mar Ecol Prog Ser 241:23-27

Rahbek C (1997) The relationship among area, elevation, and regional species richness in neotropical birds. Am Nat 149: 875-902

Rajaniemi TK (2003) Explaining productivity-diversity relationships in plants. Oikos 101:449-457

Raymond A, Kelley PH, Lutken CB (1989) Polar glaciers and life at the equator: the history of Dinantian and Namurian (Carboniferous) climate. Geology 17:408-411

Rensch B (1954) Neue Probleme der Abstammungslehre, 2nd edn. Ferdinand Enke Verlag, Stuttgart

Rex MA, Stuart CT, Hessler RR, Allen JA, Sanders HL, Wilson GDF (1993) Global-scale latitudinal patterns of species diversity in the deep-sea benthos. Nature 365:636-639

Rex MA, Stuart CT, Coyne G (2000) Latitudinal gradients of species richness in the deep-sea benthos of the North Atlantic. Proc Natl Acad Sci USA 97:4082-4085

Richer De Forges B, Koslow JA, Poore CGB (2000) Diversity and endemism of the benthic seamount fauna in the southwest Pacific. Nature 405:944-947

Rohde K (1978) Latitudinal gradients in species diversity and their causes. I. A review of the hypotheses explaining the gradients. Biol Zentrbl 97:393-403

Rohde K (1992) Latitudinal gradients in species diversity: the search for the primary cause. Oikos 65:514-527

Rohde K (1997) The larger area of the tropics does not explain latitudinal gradients in species diversity. Oikos 79: $169-172$

Rohde K (1998) Latitudinal gradients in species diversity. Area matters, but how much? Oikos 82:184-190

Rohde K (1999) Latitudinal gradients in species diversity and Rapoport's rule revisited: a review of recent work and what can parasites teach us about the causes of the gradients? Ecography 22:593-613

Rosenberg MS, Adams DC, Gurevitch J (2000) MetaWin, Version 2.0. Statistical Software for Meta-Analysis. Sinauer Associates, Sunderland, MA

Rosenzweig ML (1992) Species diversity gradients: we know more and less than we thought. J Mammal 73:715-730

Rosenzweig ML (1995) Species diversity in space and time. Cambridge University Press, Cambridge

Rosenzweig ML, Sandlin EA (1997) Species diversity and latitudes: listening to area's signal. Oikos 80:172-176

Roy K, Jablonski D, Valentine JW, Rosenberg G (1998) Marine latitudinal diversity gradients: tests of causal hypotheses. Proc Natl Acad Sci USA 95:3699-3702

Roy K, Jablonski D, Martien KK (2000a) Invariant sizefrequency distributions along a latitudinal gradient in marine bivalves. Proc Natl Acad Sci USA 97:13150-13155

Roy K, Jablonski D, Valentine JW (2000b) Dissecting latitudinal diversity gradients: functional groups and clades of marine bivalves. Proc R Soc Lond B Biol Sci 267:293-299

Ruggiero A (1999) Spatial patterns in the diversity of mammal species: a test of the geographic area hypothesis in South America. Ecoscience 6:338-354

Rutherford S, D'Hondt S, Prell S (1999) Environmental controls on the geographic distribution of zooplankton diversity. Nature 400:749-753

Sabbe K, Vanhoutte K, Lowe RL, Bergey EA, Biggs BJF, Francoeur S, Hodgson D, Vyverman W (2001) Six new Actinella (Bacillariophyta) species from Papua New Guinea, Australia and New Zealand: further evidence for widespread diatom endemism, in the Australasian region. Eur J Phycol 36:321-340

Sanders HL (1968) Marine benthic diversity: a comparative study. Am Nat 102:253-282

Santelices B, Marquet PA (1998) Seaweeds, latitudinal diversity patterns, and Rapoport's rule. Div Distr 4:71-75

Smith HG (1982) The terrestrial protozoan fauna of South Georgia. Polar Biol 1:173-179

Sokal RR, Rohlf FJ (1995) Biometry, 3rd edn. WH Freeman, New York

Stehli FG, Douglas RG, Newell ND (1969) Generation and maintenance of gradients in taxonomic diversity. Science 164:947-949

Stephens PR, Wiens JJ (2003) Explaining species richness from continents to communities: the time for speciation effect in emydid turtles. Am Nat 161:112-128

Stevens RD, Willig MR (2002) Geographical ecology at the community level: perspectives on the diversity of new world bats. Ecology 83:545-560

Storch D (2003) Comment on 'Global biodiversity, biochemical kinetics, and the energy-equivalence rule'. Science 299:346

Swearer SE, Caselle JE, Lea DW, Warner RR (1999) Larval retention and recruitment in an island population of a coral-reef fish. Nature 402:799-802

Terborgh J (1973) On the notion of favorableness in plant ecology. Am Nat 107:481-501

Thorson G (1952) Zur jetzigen Lage der marinen BodentierÖkologie. Zool Anz Suppl 16:276-327

Thorson G (1957) Bottom communities (sublittoral or shallow shelf). Geol Soc Am Mem 67:461-534 
Victor BC, Wellington GM (2000) Endemism and the pelagic larval duration of reef fishes in the eastern Pacific Ocean. Mar Ecol Prog Ser 205:241-248

Waide RB, Willig MR, Steiner CF, Mittelbach G, Gough L, Dodson SI, Juday JP, Parmenter R (1999) The relationship between productivity and species richness. Annu Rev Ecol Syst 30:257-300

Whittaker RH (1960) Vegetation of the Siskiyou Mountains, Oregon and California. Ecol Monogr 30:279-338

Wilkinson DM (2001) What is the upper size limit for cosmopolitan disribution in free-living microorganisms? J Biogeogr 28:285-291

Williams A, Koslow JA, Last PR (2001) Diversity, density and community structure of the demersal fish fauna of the continental slope off western Australia (20 to $\left.35^{\circ} \mathrm{S}\right)$. Mar Ecol Prog Ser 212:247-263

Willig MR, Lyons SK (1998) An analytical model of latitudinal gradients of species richness with an empirical test for marsupials and bats in the new world. Oikos 81:93-98

Wilson GDF (1998) Historical influences on deep-sea isopod

Editorial responsibility: Andrea Belgrano,

Santa Fe, New Mexico, USA diversity in the Atlantic Ocean. Deep-Sea Res II 45: 279-301

Woodd-Walker RS, Ward P, Clarke A (2002) Large-scale patterns in diversity and community structure of surface water copepods from the Atlantic Ocean. Mar Ecol Prog Ser 236:189-203

Worm B, Lotze HK, Hillebrand H, Sommer U (2002) Consumer versus resource control of species diversity and ecosystem functioning. Nature 417:848-851

Worm B, Lotze HK, Myers RA (2003) Predator diversity hotspots in the blue ocean. Proc Natl Acad Sci USA 100: 9884-9888

Wright DH (1983) Species-energy theory: an extension of species-area theory. Oikos 41:496-506

Zobel M (1997) The relative role of species pools in determining plant species richness: an alternative explanation of species coexistence? Trends Ecol Evol 12:266-269

Zobel M, Otsus M, Liira J, Moora M, Möls T (2000) Is smallscale species richness limited by seed availability or microsite availability? Ecology 81:3274-3282

Submitted: April 16, 2003; Accepted: January 27, 2004

Proofs received from author(s): May 17, 2004 